\title{
Pesquisa de Anticorpos Anti-Borrelia e Anti-Babesia em Soro de Crianças com Manifestações Clínicas e Epidemiologia Compatíveis com a Doença de Lyme-Simile no Estado de Mato Grosso do Sul
}

\section{Detection of Anti-Borrelia and Anti-Babesia Antibodies in the Serum of Children with Clinical Manifestations and Compatible Epidemiolosy with Lyme-Like Disease in the State of Mato Grosso do Sul}

\author{
Erica Naomi Naka ${ }^{(1)}$, Izaias Pereira da Costa ${ }^{(2)}$, César Augusto Brandão Arão ${ }^{(3)}$, \\ Cleber Oliveira Soares ${ }^{(4)}$, Natalino Hajime Yoshinari( ${ }^{(5)}$
}

\section{RESUMO}

A ocorrência de manifestações clínicas e laboratoriais semelhantes às encontradas na doença de Lyme $\mathrm{e}$ da coinfecção com a babesiose já foi demonstrada em trabalhos anteriores em adultos, porém não existem estudos desta natureza em crianças. Objetivo: Caracterizar o perfil clínico-epidemiológico da síndrome de Lyme-Símile em crianças do Estado de Mato Grosso do Sul e avaliar a prevalência dos anticorpos anti-Borrelia burgdorferie anti-Babesia bovis no soro de pacientes que preencheram os critérios estabelecidos. Métodos: 100 pacientes entre 9 meses e 16 anos de idade foram submetidos à pesquisa dos anticorpos pela técnica de ELISA e a soroprevalência foi comparada com um grupo-controle. Resultados: Positividade para anticorpos anti-B. burgdorferi ocorreu em $27 \%$ dos pacientes com suspeita clínica, sendo $17 \% \operatorname{IgM}$ e $12 \%$ IgG. As manifestações articulares ocorreram em 21 pacientes, as manifestações cutâneas em três pacientes e as manifestações neurológicas em três pacientes. A prevalência de anticorpos contra $B$. burgdorferi nos pacientes do grupo-controle foi de $15 \%(\mathrm{p}<0,05)$. Os anticorpos anti-B. bovis estiveram presentes em $24 \%$ dos pacientes suspeitos e em $3 \%$ do grupo-controle $(\mathrm{p}<0,05)$. Concomitância dos anticorpos ocorreu em 10 pacientes com suspeita clínica e em nenhum controle. Conclusão: Os resultados deste estudo evidenciam a etiologia de caráter infeccioso e reacional das manifestações clínicas encontradas

\begin{abstract}
The occurence of clinical and laboratory manifestations similar to the Lyme disease and the coinfection with babesiosis was already demonstraded in previous researches with adult patients. However, there are no studies in children. Objective: To identify the clinical-epidemiological profile of the Lyme Simile Syndrome in children of the State of Mato Grosso do Sul and to evaluate the prevalence of antibodies against Borrelia burgdorferi and Babesia bovis in the serum of patients that had fulfilled the established criteria. Methods: One hundred patients (age range: 9 months and 16 years-old) were screened for the presence of those antibodies, using ELISA, comparing to a control group. Results: Antibodies against B. burgdoferi were found in 27\% of the patients with a clinical picture. The articular manifestations occurred in 21 patients, cutaneous in 3 and neurological in 3. The prevalency in the control group was $15 \%(p<0.05)$. The antibodies for Babesia bovis were present in $24 \%$ of suspect patients and in $3 \%$ of the control group $(p<0.05)$. Concomitance of the two antibodies occurred in 10 patients with clinical suspect and no one of control group. Conclusion: The results found in this study suggest the infective and reactive character of the clinical manifestations of the patients, which can characterize a Syndrome, which possibly occurs in the presence of multiple
\end{abstract}

Recebido em 6/2/2007. Aprovado, após revisão, em 16/3/2008. Declaramos a inexistência de conflitos de interesse.

Este estudo teve auxílio financeiro da Fundação de Apoio à Pesquisa (Fape) da Sociedade Brasileira de Reumatologia (SBR)

Serviço de Reumatologia do Hospital Universitário da Faculdade de Medicina da Universidade Federal de Mato Grosso do Sul (Famed-UFMS)

1. Mestre e reumatologista pediatra responsável pela Unidade de Reumatologia Pediátrica do Serviço de Reumatologia e de Pediatria do Hospital Universitário da Universidade Federal de Mato Grosso do Sul (UFMS).

2. Doutor e professor-associado do Departamento de Clínica Médica da Faculdade de Medicina (Famed)/UFMS, coordenador do Programa de Residência Médica em Reumatologia da UFMS e chefe do Serviço de Reumatologia do Hospital Universitário da UFMS.

3. Mestre e farmacêutico bioquímico do Laboratório Central de Saúde Público do Estado de Mato Grosso do Sul (Lacen-MS).

4. Doutor e chefe adjunto de Pesquisa e Desenvolvimento da Empresa Brasileira de Pesquisa Agropecuária (Embrapa) Gado de Corte de Campo Grande-MS.

5. Doutor e professor livre docente da Faculdade de Medicina da Universidade de São Paulo (FMUSP), responsável pelo Laboratório de Imunologia (LIM17) da FMUSP e pela pesquisa da síndrome de Lyme-Simile no Brasil.

Endereço para correspondência: Erica Naomi Naka, Rua Paulo Freire, 224, Jardim América, CEP 79080-140, Campo Grande, MS, e-mail: nakaerica@yahoo.com.br 
nos pacientes, podendo caracterizar uma síndrome, que possivelmente ocorra na presença de múltiplos microrganismos e está relacionada com carrapatos. Foi encontrada freqüência superior de anticorpos contra Borrelia e Babesia nos pacientes em relação aos controles. Embora pequena, essa diferença foi estatisticamente significante. Este achado não atesta que o quadro clínico dos pacientes seja causado por espécies de Borrelia ou Babesia, mas levantam a possibilidade de participação de algum agente infeccioso que possa estar relacionado a esses microrganismos. Os estudos devem prosseguir para melhorar a delineação desta síndrome em nosso meio, assim como isolar o agente etiológico.

Palavras-chaves: Borrelia burgdorferi, Babesia bovis, Lyme-simile, crianças.

\section{INTRODUÇÃO}

A borreliose de Lyme é uma infecção multissistêmica causada por diferentes espécies do gênero Borrelia, denominadas de Borrelia burgdorferi sensu lato, e transmitida por picadas de carrapatos da família Ixodidae e similares ${ }^{(1,2)}$. É uma doença infecciosa emergente de distribuição mundial $^{(3-6)}$, e na Europa foram identificados outros agentes etiológicos, como a Borrelia garinii e a Borrelia afzelii, sendo a última isolada também no continente asiático ${ }^{(4)}$. Nos Estados Unidos (EUA), a Borrelia burgdorferi stricto sensu é o principal agente etiológico ${ }^{(3)}$.

Em virtude do caráter multissistêmico da doença, convencionou-se chamar esta entidade clínica como doença de Lyme (DL) ou borreliose de Lyme (BL) ${ }^{(2)}$. Anteriormente foi denominada artrite de Lyme, pois em 1977 ocorreu uma epidemia com manifestações clínicas semelhantes a uma doença infecciosa, caracterizada por artrite oligoarticular e eritema migratório (EM), em uma zona rural da cidade de Lyme (Connecticut, EUA) ${ }^{(7)}$.

Em vista do desconhecimento da ocorrência da DL no Brasil, criou-se um projeto para a pesquisa da doença. Foi formada uma equipe multidisciplinar para a investigação da DL no Hospital das Clínicas da Faculdade de Medicina da Universidade de São Paulo (HC-FMUSP), com a estruturação de um laboratório específico para o diagnóstico, realização de exames sorológicos e cultivo de Borrelia burgdorferi( ${ }^{(8)}$. Os primeiros casos de DL com manifestações extracutâneas e sorologia positiva foram descritos em $1992^{(9)}$. Em 1993, a doença foi descrita em dois irmãos que haviam viajado para o município de Cotia, no Estado de São Paulo, e apresentaram quadro típico de EM crônico (EMC), além de envolvimentos articular e muscular, com sorologia positiva para Borrelia burgdorferi e boa resposta à antibioticoterapia ${ }^{(10)}$. A partir daquele ano, foram relata- microorganisms that can be associated with tick-borne. It was found a higher frequency of antibodies against borrelia and babesia in patients in relation to the controls. Although small, this difference was statistically significant. This finding does not certify that the clinical features of patients is caused by species of borrelia or babesia, but raised the possibility of involvement of some infectious agent that could be related to these microorganisms. The studies should continue in order to improve the delineation of this syndrome and to try the isolation of the etiologic agent in our State.

Keywords: borrelia burgdorferi, babesia bovis, lyme-like, children.

dos novos casos de DL e preconizada a técnica de western blotting (WB), com a utilização da Borrelia burgdorferi como substrato ${ }^{(11-13)}$.

Em 1998, 16 pacientes com manifestações clínicas típicas da DL apresentaram positividade para anticorpos contra Borrelia burgdorferi sensu lato por meio de ensaio imunoenzimático e WB em Mato Grosso do Sul(14). E em 1996 havia sido descrito neste Estado o primeiro caso de meningite de Lyme no Brasil ${ }^{(15)}$. Foram identificados possíveis reservatórios e vetores dessa borreliose na região, com a visualização de espiroquetídeos semelhantes ao gênero Borrelia sp. em cultura de amostras de sangue de animais silvestres (marsupiais e roedores) e de macerado de carrapatos do gênero Amblyomma sp. ${ }^{(16)}$.

Em 2005, após 15 anos de estudo, Yoshinari et al. ${ }^{(17)}$ consideraram que as manifestações clínicas e sorológicas, até então descritas no Brasil, constituíam uma síndrome clínica que exibiria aspectos clínicos compatíveis aos de infecções e enfermidades reacionais, cujas manifestações clínicas eram semelhantes às encontradas na DL. Seria transmitida por carrapatos e causada por microrganismos "latentes" constituídos de Mycoplasmas, Chlamídias e espiroquetas, observados laboratorialmente. Por essa razão, propôs-se as denominações de síndrome de Lyme-simile (SLS) ou complexo infecto-reacional do carrapato ou síndrome de Baggio-Yoshinari, em homenagem aos primeiros pesquisadores no Brasil ${ }^{(18)}$.

Em Mato Grosso do Sul, um projeto em rede foi realizado pela Empresa Brasileira de Pesquisa Agropecuária (Embrapa) Gado de Corte de Campo Grande, pela Universidade Federal de Mato Grosso do Sul (UFMS), pela Universidade de São Paulo (USP) e pela Universidade Federal do Rio de Janeiro (UFRJ). Foi observada grande proporção de bovinos das fazendas de seis municípios do interior de Mato Grosso do Sul com sorologia positiva, tan- 
to para B. burgdorefi $(68,8 \%$ a $99,2 \%)$ quanto para Babesia bovis $(71,2 \%$ a $98,4 \%)$. Houve ainda coexistência de ambas em $54,5 \%$ a $97 \%$ nos bovinos ${ }^{(19)}$.

A partir da inoculação da bactéria na pele por meio da picada do carrapato, as manifestações clínicas da DL são caracterizadas por três estágios, conforme a classificação proposta pelo Centro de Controle de Doenças e Prevenção $(C D C)^{(20,21)}$. O estágio primário é caracterizado por $\mathrm{EMC}^{(22,23)}$ e manifestações sistêmicas inespecíficas; o estágio secundário, após semanas a meses da infecção, é caracterizado com vários tipos de acometimentos: cardíaco, articular, do sistema nervoso central (SNC) e, ocasionalmente, comprometimento oftalmólogico; e o estágio terciário, que aparece meses a anos após a infecção, é caracterizado freqüentemente por artrite crônica ${ }^{(24)}$, acrodermatite ${ }^{(25,26)}$ e encefalomielite ${ }^{(27,28)}$.

O procedimento mais empregado para o diagnóstico laboratorial é a pesquisa dos anticorpos contra Borrelia burgdorferi(29-31). O ensaio imunoenzimático (ELISA) indireto e WB são os mais utilizados. O WB tem sido empregado secundariamente para definição do resultado em casos de dúvida no método ELISA ${ }^{(32,33)}$. O Centro de Referência para a DL no Brasil, do Laboratório de Investigação da Interação entre Microorganismo e Artrite, da Disciplina de Reumatologia da FMUSP-SP ${ }^{(8,9)}$, preconizou os critérios clínicos e epidemiológicos para o diagnóstico da SLS: epidemiologia positiva com história de picada ou contato com carrapato ou exposição em áreas de mata (litorânea ou campo) e quadro clínico compatível (com a presença de EM ou acometimento de pelo menos um dos sistemas: nervoso, osteoarticular ou cardíaco); sorologia positiva no ELISA com títulos maiores que $1 / 100$ para IgM e $1 / 400$ para IgG ou presença de WB positivo (com pelo menos duas bandas específicas para $\operatorname{IgM}$ ou quatro bandas específicas para IgG, ou concomitância de uma banda $\operatorname{Ig} M$ e duas $\operatorname{IgG}$ ).

A coexistência de anticorpos para borreliose e babesiose humana têm sido observada em soros de pacientes de áreas de risco para estas enfermidades, sem significar reações cruzadas $^{(34)}$. A babesiose humana é uma zoonose que clinicamente assemelha-se à malária, causada por um protozoário intraeritrocítico do gênero Babesia, que afeta tanto o homem quanto diferentes animais domésticos e silvestres. $\mathrm{O}$ homem adquire a doença acidentalmente por meio da picada de carrapatos ou por transfusões sangüíneas ${ }^{(35,36)} \mathrm{e}$, na maioria dos casos, a infecção é assintomática, exceto em pacientes imunossuprimidos ${ }^{(34)}$. A presença de anticorpos em indivíduos assintomáticos tem sido encontrada em diferentes estudos sorológicos ${ }^{(21,37)}$.

A coinfecção entre os agentes da BL e da babesiose foi confirmada em 59 pacientes brasileiros com diagnóstico de BL quando o ELISA e o WB para Babesia bovis foram realizados nas amostras de sangue estocados. Foi demonstrada maior freqüência de anticorpos contra $B$. bovis nesses pacientes em comparação com a população normal ${ }^{(34)}$.

O Estado de Mato Grosso do Sul apresenta todas as condições favoráveis de clima, fauna e flora para a presença e disseminação da SLS. A intensa atividade agropecuária, o convívio do homem com os animais domésticos e a valorização de atividades ao ar livre favorecem a disseminação de agentes infecciosos transmitidos por carrapatos, propiciando o surgimento e o ressurgimento de diferentes agentes etiológicos ${ }^{(14,16)}$.

Como não existem estudos dessa natureza em crianças, este estudo propõe-se a caracterizar o perfil clínico e epidemiológico da SLS e a ocorrência de anticorpos anti-Borrelia burgdorferi e anti-Babesia bovis em crianças do estado de Mato Grosso do Sul e comparar a soroprevalência destes anticorpos com um grupo-controle normal.

\section{PACIENTES E MÉTODOS}

Ampla divulgação foi realizada nos meses de janeiro e fevereiro de 2004, com esclarecimentos sobre a pesquisa e solicitação da colaboração dos profissionais de saúde para o encaminhamento de crianças e adolescentes com os critérios clínicos e epidemiológicos para a SLS atendidos em postos de saúde, pronto-socorros e consultórios privados da capital e do interior do Estado de Mato Grosso do Sul. A seleção dos pacientes ocorreu no período compreendido entre os meses de março de 2004 e junho de 2005 (15 meses).

\section{CRITÉRIOS DE INCLUSÃO}

As crianças e os adolescentes com idade até 16 anos com suspeita clínica foram encaminhadas ao Ambulatório de Reumatologia Pediátrica do Hospital Universitário da UFMS, para avaliação dos critérios clínicos e epidemiológicos preconizados pelo Centro de Referência para a DL no Brasil ${ }^{(8,9)}$. Depois de explicação detalhada da pesquisa, foram realizadas a leitura e a assinatura do termo de consentimento livre e esclarecido aos responsáveis legais dos pacientes. O consentimento livre e esclarecido foi revisado e aprovado pelo Comitê de Ética em Pesquisa com Seres 
Humanos da UFMS. Um protocolo especialmente criado para a pesquisa foi preenchido, no qual constaram dados como sexo, idade, procedência (urbana ou rural), história de picada de carrapato ou contato previamente ao início dos sintomas, manifestações clínicas e duração, assim como diagnósticos e tratamentos anteriores.

Para o controle normal dos ensaios laboratoriais, 100 amostras de soros de crianças e adolescentes normais sem manifestações clínicas, doenças intercorrentes e epidemiologia compatível com a SLS foram selecionadas. Estes pacientes procuraram o ambulatório geral de pediatria do Hospital Universitário da UFMS para acompanhamento de rotina, e foram escolhidos para constituir uma amostra pareada em relação à idade e ao sexo dos pacientes já selecionados com suspeita clínica. Foram submetidos ao mesmo protocolo e exames.

\section{CRITÉRIOS DE EXCLUSÃO}

A presença de patologias intercorrentes que poderiam interferir na avaliação sorológica, como doenças auto-imunes, neoplasias malignas, sífilis, toxoplasmose, tuberculose, blastomicose ou outras doenças infecciosas crônicas foram critérios de exclusão, assim como os pacientes que apresentaram positividade para anticorpo antinuclear (FAN), fator reumatóide (FR), antiestreptolisina O (ASLO), sorologia para toxoplasmose e sífilis.

Os exames complementares do protocolo incluíram ainda hemograma completo, provas de fase aguda - velocidade de hemossedimentação (VHS) e/ou mucoproteínas e/ou proteína C reativa e/ou eletroforese de proteínas. Outros exames específicos foram solicitados nos casos em que foi necessário o diagnóstico diferencial com outras doenças. As amostras de soro foram congeladas a $-20^{\circ} \mathrm{C} \mathrm{e}$ transportadas em gelo ao Laboratório de Sanidade Animal da Embrapa Gado de Corte de Campo Grande, para a realização de pesquisa de anticorpos contra Borrelia burgdorferi e Babesia bovis, pelo método de ELISA.

\section{PESQUISA DE ANTICORPOS ANTI-BORRELIA BURGDORFERI IGG E IGM POR ELISA}

Foram utilizados como substratos antigênicos sonicados totais da Borrelia burgdorferi stricto sensu cepa americana G 39/40 na concentração de 4,8 mg/ml, mantidas no Centro de referência para a BL, no Brasil. As análises por ELISA indireto para detecção de anticorpos contra B. burgdorferi foram procedidas segundo protocolo de Yoshinari et al. ${ }^{(9)}$ :
Foram sensibilizadas duas placas de 96 orifícios (Immulon I), uma para IgG e outra para IgM com o antígeno (sonicado total de Borrelia burgdorferi cepa G39/40, na concentração de $15 \mu \mathrm{g} / \mathrm{ml}$ ) diluído em tampão carbonato $\mathrm{pH}$ 9,6 e adicionado $100 \mu \mathrm{lem}$ cada orifício. A placa foi incubada em câmara úmida, a $4{ }^{\circ} \mathrm{C}$ overnight. No dia seguinte, depois de desprezado o sobrenadante, a placa foi lavada por três vezes com PBS Tween (PBST) $0,05 \%$ pH 7,4 . Bloqueada a placa com a adição da solução protéica feita com leite desnatado a $5 \%$ diluído em PBST $0,05 \%$ e distribuído $100 \mu \mathrm{l} \mathrm{em} \mathrm{cada} \mathrm{orifício} \mathrm{da} \mathrm{placa.}$ A placa foi incubada em câmara úmida, por 1 hora, à temperatura ambiente. Neste intervalo, foi preparada a diluição do soro padrão positivo, controles negativos $\mathrm{e}$ soros teste, utilizando-se o mesmo tampão. Após 1 hora, foi retirada a placa da câmara úmida e lavada por três vezes com PBST $0,05 \%$ pH 7,4. Na primeira coluna da placa, foi adicionado o soro padrão positivo em oito diluições crescentes a partir de 1:400 (IgG) ou 1:100 (IgM), em PBST 0,05\% com 5\% de leite desnatado pH 7,4. Na segunda e terceira coluna, os oito controles negativos em duplicata na mesma diluição. Nos dois primeiros orifícios da quarta coluna, foi adicionado apenas $200 \mu \mathrm{l}$ do tampão (branco). O restante da placa foi utilizado para os soros suspeitos na diluição de $1 / 100$ para $\operatorname{IgM}$ ou $1 / 400$ para IgG. A placa foi incubada novamente em câmara úmida, por 1 hora, à temperatura ambiente e após esse período, lavada por três vezes com PBST 0,05\% pH 7,4 e adicionado o conjugado, soro de cabra antiimunoglobulina específica humana (anti-IgM ou anti-IgG) conjugado à enzima fosfatase alcalina (Sigma), diluído a 1:1000 em PBST com leite desnatado $\mathrm{pH}$ 7,4 e distribuído $100 \mu$ por poço. A placa foi novamente incubada em câmara úmida, por 1 hora, à temperatura ambiente e retirada após esse período e lavada por três vezes com PBST 0,05\% pH 7,4. A solução substrato revelador - para-nitro-fenil-fosfato (PNPP), na concentração de $1 \mathrm{mg} / \mathrm{ml}$, diluído em tampão glicina pH 10,5 - foi distribuído, sendo $100 \mu \mathrm{l} \mathrm{em} \mathrm{cada}$ orifício. Realizada a leitura em espectrofotômetro em comprimento de onda de $405 \mathrm{~nm}$ no momento em que o primeiro controle positivo atingiu a densidade óptica (DO) de 0,5 para $\operatorname{IgM}$ e 1,0 para IgG. Interpretação dos resultados: uma amostra foi considerada positiva se apresentasse uma DO (densidade óptica) igual ou maior ao valor do cut-off, que foi obtido pela média dos valores de DOs dos controles negativos mais três vezes o desvio padrão desses valores, garantindo um nível de confiança 
de $99,8 \%$. Os valores em DOs expressos pelo espectrofotômetro para as microplacas foram convertidos em títulos, utilizando-se, para esse fim, um gráfico de calibração do título, em papel milimetrado. O título considerado positivo para $\operatorname{IgG}$ foi maior ou igual a $1 / 400$ e para $\operatorname{IgM}$ maior ou igual a $1 / 100$.

\section{PESQUISA DE ANTICORPOS ANTI-BABESIA}

\section{BOVIS IGG E IGM POR ELISA}

$O$ antígeno de Babesia bovis foi obtido segundo metodologia descrita por Madruga et al. ${ }^{(29)}$. As análises por ELISA indireto para detecção de anticorpos contra B. bovis foram procedidas segundo o protocolo de Yoshinari ${ }^{(34)}$ :

Foram sensibilizadas duas placas de 96 orifícios (Immulon I), uma para IgG e outra para IgM com o antígeno de Babesia bovis, na concentração de 7,5 $\mu \mathrm{g} / \mathrm{ml}$ diluído em tampão carbonato pH 9,6 e adicionado $100 \mu \mathrm{lem}$ cada orifício. A placa foi incubada em câmara úmida, a $4{ }^{\circ} \mathrm{C}$ overnight. No dia seguinte, a placa foi lavada por três vezes com PBST 0,05\% pH 7,4 e adicionada a solução bloqueio na placa - solução protéica feita com soro eqüino a $1 \%$ diluído em PBST 0,05\% - e distribuído $100 \mu \mathrm{l}$ /poço. A placa foi incubada novamente em câmara úmida, por 1 hora, à temperatura ambiente e, enquanto se aguardava, foram diluídos os soros testes e oito controles negativos na diluição de $1 / 100$ para a placa de $\operatorname{IgM}$ e $1 / 400$ para IgG. Foi diluído $1,25 \mu \mathrm{l}$ de soro teste em $500 \mu \mathrm{l}$ de PBST com $1 \%$ de soro eqüino para a placa de $\mathrm{IgG}$ e $5 \mu \mathrm{l}$ de soro teste em $500 \mu \mathrm{l}$ de PBST com $1 \%$ de soro eqüino para a placa de IgM. Após 1 hora, foi retirada a placa da câmara úmida e lavada por três vezes com PBST 0,05\% pH 7,4 e foram distribuídos $100 \mu \mathrm{l}$ de cada soro-teste previamente diluído em cada poço da placa, a partir da quarta coluna, após dois poços brancos (somente com soro eqüino a $1 \%$ diluído em PBST 0,05\%). Os oito soros-controle negativos foram distribuídos em duplicata na segunda e terceira colunas. O controle positivo foi diluído na primeira coluna da placa, em oito diluições crescentes a partir de 1:400 ( $\operatorname{IgG}$ ) ou $1: 100(\operatorname{IgM})$, em PBST $0,05 \%$ com soro eqüino a $1 \% \mathrm{pH} 7,4$. A placa foi incubada novamente em câmara úmida, por duas horas, à temperatura ambiente e, após esse período, lavada por três vezes com PBST 0,05\% pH 7,4 . O conjugado, soro de cabra anti-IgM ou anti-IgG humano conjugado à enzima fosfatase alcalina (Sigma), diluído a 1:2000 em PBST com soro eqüino a 1\% diluído em PBST foi distribuído, sendo $100 \mu$ por poço. A placa foi novamente incubada em câmara úmida, por 1 hora, à temperatura ambiente e retirada após esse período e lavada por três vezes com PBST 0,05\% pH 7,4. Após o preparo da solução substrato - para-nitro-fenil-fosfato (PNPP), na concentração de $1 \mathrm{mg} / \mathrm{ml}$, diluído em tampão glicina $\mathrm{pH}$ 10,5 - $100 \mu \mathrm{l}$ desta foi distribuída em cada poço. Realizada a leitura em espectrofotômetro, em comprimento de onda de $405 \mathrm{~nm}$, no momento em que o primeiro controle positivo atingiu a DO de 0,5 para IgM e 1,0 para IgG.

\section{INTERPRETAÇÃO DOS RESULTADOS}

Uma amostra seria considerada positiva se apresentasse uma DO igual ou maior ao valor do cut-off (obtido pela média dos valores de DOs dos controles negativos mais três vezes o desvio-padrão desses valores), garantindo o nível de confiança de $99,8 \%$. Os valores em DOs expressos pelo espectrofotômetro para as microplacas foram convertidos em títulos, utilizando-se, para esse fim, um gráfico de calibração do título, em papel milimetrado. O título foi considerado positivo para IgG e para IgM se maior ou igual a $1 / 800$.

O método estatístico utilizado para comparar os resultados sorológicos entre o grupo de pacientes com suspeita clínica e o grupo-controle foi o teste do qui-quadrado $\left(\chi^{2}\right)$ para valores significativos com $\mathrm{p}<0,05$.

\section{RESULTADOS}

Foram selecionadas 131 pacientes, porém 25 foram retirados do protocolo por causa da positividade de um dos exames (FAN, FR, ASLO, sorologia para toxoplasmose ou sífilis) e 6 pacientes foram excluídos por preencherem critérios para outras doenças durante a seleção.

A idade dos 100 pacientes com suspeita clínica de SLS variou de 9 meses a 16 anos (média de 7 anos e 3 meses e mediana de 7 anos e 1 mês) e do grupo-controle de 10 meses a 16 anos (média de 7 anos e 5 meses e mediana de 6 anos e 8 meses). Dos pacientes com suspeita de SLS, $47 \%$ eram do sexo masculino e $53 \%$ feminino. No grupocontrole, $46 \%$ do sexo masculino e $54 \%$ do feminino. Não houve diferença estatisticamente significante entre os dois grupos com relação à idade e ao sexo. Dos pacientes com suspeita clínica, $68 \%$ eram procedentes da região urbana da capital e $32 \%$ da zona rural de cidades do interior do estado. Todos os pacientes do grupo-controle eram provenientes da zona urbana da capital.

Afirmaram que haviam sido picados por carrapatos 20 pacientes e 80 pacientes apresentaram contato direto com animais infestados por carrapato. $\mathrm{O}$ tempo decorrido entre a picada e o início dos sintomas variou de sete dias a seis 
meses. O local de picada mais freqüente foi nos membros inferiores $(50 \%)$.

As manifestações clínicas encontradas nos $100 \mathrm{pa}$ cientes com suspeita clínica de SLS foram: manifestações articulares em 78\% (59 pacientes com artrite aguda e 19 com artrite crônica); manifestações cutâneas em 11\% (dois pacientes com EM, três com eritema anular secundário, quatro com esclerodermia linear, uma paciente com esclerodermia em placa tipo morféia e uma paciente com esclerodermia tipo golpe de sabre); manifestações neurológicas em 10\% (seis pacientes com paralisia facial, três pacientes com meningite linfocitária aguda e um com radiculoneurite) e manifestações cardiovasculares em uma paciente (pericardite).

O hemograma não demonstrou nenhuma anormalidade importante. As provas inflamatórias foram normais em $\mathbf{5 8 \%}$ dos pacientes, com elevações variáveis em $42 \%$ dos pacientes. O exame do liquor realizado nos três pacientes com meningite evidenciou leucocitose com predomínio de linfomononucleares, bacterioscopia e cultura negativas. No paciente com radiculoneurite, houve aumento de proteínas no liquor sem alterações da citologia global e diferencial. A biópsia cutânea foi realizada em seis pacientes com lesões cutâneas crônicas, sendo encontradas características histopatológicas compatíveis com esclerodermia cutânea em todos.

Dos 100 pacientes com suspeita clínica de SLS, 27 apresentaram sorologia positiva para Borrelia burgdorferi, sendo as manifestações clínicas encontradas: artrite em 21 pacientes ( 16 com artrite aguda e cinco com artrite crônica); manifestações cutâneas em três pacientes (um com EM e dois com esclerodermia - um linear e outro golpe de sabre); manifestações neurológicas em três pacientes (meningite linfocitária em um paciente e dois com paralisia facial).
Dos 27 pacientes, 10 apresentaram concomitantemente anticorpos contra Babesia bovis.

Apresentaram anticorpos contra Babesia bovis apenas 14 pacientes, sendo as seguintes manifestações clínicas encontradas: 10 pacientes com acometimento articular; dois pacientes com acometimento cutâneo (um com EM e outro com esclerodermia em placa tipo morféia); um paciente com acometimento neurológico (paralisia facial) e um paciente com pericardite. Os resultados das sorologias e as características dos pacientes estão resumidas nas Tabelas 1 a 6 , a seguir.

A positividade da sorologia para B. burgdorferi nos soros de pacientes com suspeita de SLS para os anticorpos da classe $\operatorname{IgG}$ e IgM mostraram-se aumentadas quando comparadas com o grupo-controle. Nesses pacientes, o teste ELISA contra B. burgdorferi mostrou positividade de $12 \%$ para anticorpos da classe IgG e $17 \%$ para IgM. O grupo-controle apresentou positividade para B. burgdorferi em $8 \%$ tanto para anticorpos da classe IgG quanto para $\operatorname{IgM}$. Houve diferença significativa estatisticamente entre os dois grupos $(\mathrm{p}<0,05)$.

A positividade da sorologia para B. bovis nos soros de pacientes com SLS para o anticorpo IgG (24\%) mostrouse aumentada quando comparada com o grupo-controle $(3 \%)$. Houve diferença significativa estatisticamente entre os dois grupos $(\mathrm{p}<0,05)$. Apenas 1 paciente do grupo com suspeita de SLS apresentou positividade do anticorpo $\operatorname{IgM}(1: 3200)$ e nenhum paciente do grupo-controle. No grupo de pacientes com quadro clínico e epidemiologia compatíveis com a SLS houve concomitância na positividade da sorologia para B. burgdorferi e B. bovis em 11 pacientes. No grupo-controle, não houve concomitância em nenhum caso.

Tabela 1

Pacientes com acometimento cutâneo com Sorologia positiva para Borrelia Burgdorferi (Bo) E/Ou Babesia Bovis (BA) PElo ELISA

\begin{tabular}{|c|c|c|c|c|c|c|c|}
\hline $\mathrm{N}^{\circ}$ & Idade & Sexo & Procedência & Tipo de lesão & Duração da doença & Picada ou contato & Sorologia (ELISA) \\
\hline 1 & 2 a 3 m & $\mathrm{F}$ & Interior & Eritema migratório & 3 dias & Picada há 7 dias & $\begin{array}{l}\text { IgM Bo } 1 / 100 \\
\text { IgG Ba } 1 / 800\end{array}$ \\
\hline 2 & $14 \mathrm{a}$ & $\mathrm{F}$ & Capital & Esclerodermia morféia & 5 anos & Contato & IgG Ba 1/800 \\
\hline 3 & $7 \mathrm{a}$ & $\mathrm{F}$ & Capital & Esclerodermia em golpe de sabre & 4 anos & Contato & $\begin{array}{l}\text { IgG Bo } 1 / 800 \\
\text { IgM Bo } 1 / 200 \\
\text { IgG Ba } 1 / 1600 \\
\text { IgM Ba1/3200 }\end{array}$ \\
\hline 4 & $14 \mathrm{a}$ & $\mathrm{F}$ & Capital & Esclerodermia linear & 5 anos & Contato & IgG Bo $1 / 400$ \\
\hline 5 & $3 a$ & M & Interior & Eritema migratório & 5 dias & Picada há 7 dias & $\operatorname{IgG~Ba~1/1600~}$ \\
\hline
\end{tabular}

ELISA = Enzyme-linked immunosorbent assay; $a=$ anos; $m=$ meses; $M=$ sexo masculino; $F=$ sexo feminino; IgM = imunoglobulina $M$; IgG = imunoglobulina $\mathrm{G}$. 
Tabela 2

Pacientes COM MONOARTrite Aguda E SORologia POSITIVA Para Borrelia Burgdorferi (Bo) E/Ou Babesia Bovis (BA) PELO ELISA

\begin{tabular}{|c|c|c|c|c|c|c|c|}
\hline $\mathrm{N}^{\circ}$ & Idade & Sexo & Procedência & Articulação acometida & Duração da doença & Picada ou contato & Sorologia (ELISA) \\
\hline 6 & 6 a $6 \mathrm{~m}$ & M & Interior & Quadril E de repetição $(3 x)$ & 1 mês & Picada há 6 meses & $\operatorname{Ig} M$ Bo1/100 \\
\hline 7 & 6 a $1 \mathrm{~m}$ & M & Interior & Tornozelo $\mathrm{E}$ & 10 dias & Contato & $\operatorname{IgM}$ Bo1/100 \\
\hline 8 & 10 a 3 & $\mathrm{~F}$ & Capital & Joelho E & 1 mês & Contato & $\operatorname{Ig} M$ Bo1/100 \\
\hline 9 & $8 \mathrm{a}$ & $\mathrm{F}$ & Capital & Tornozelo E & 15 dias & $\begin{array}{c}\text { Picada há } \\
2 \text { meses }\end{array}$ & $\operatorname{IgG} \mathrm{Ba} 1 / 800$ \\
\hline 10 & 2 a $7 \mathrm{~m}$ & $\mathrm{~F}$ & Interior & Quadril E & 12 dias & Contato & IgG Ba 1/800 \\
\hline 11 & 8 a $11 \mathrm{~m}$ & M & Capital & Joelho D & 5 meses antes & Contato & $\begin{array}{l}\text { IgM Bo1/100 } \\
\text { IgG Ba } 1 / 800\end{array}$ \\
\hline 12 & $12 \mathrm{a}$ & M & Capital & Tornozelo E & 7 dias & Contato & $\operatorname{IgG~Ba~1/800~}$ \\
\hline 13 & $8 a$ & M & Capital & Tornozelo E & 7 dias & Contato & $\begin{array}{l}\text { IgM Bo1/100 } \\
\text { IgG Ba } 1 / 800\end{array}$ \\
\hline 14 & 2 a $2 \mathrm{~m}$ & $\mathrm{~F}$ & Interior & Quadril D & 6 dias & Picada há 7 dias & $\begin{array}{l}\text { IgG Bo } 1 / 400 \\
\text { IgM Bo } 1 / 200\end{array}$ \\
\hline 15 & 8 a $4 \mathrm{~m}$ & M & Capital & Quadril D & 5 dias & Contato & IgG Ba 1/12800 \\
\hline 16 & 4 a $8 \mathrm{~m}$ & M & Capital & Quadril D & 15 dias & Picada há 1 mês & $\operatorname{IgG~Ba~1/800~}$ \\
\hline 17 & $7 \mathrm{a}$ & M & Capital & Quadril D & 18 dias & Contato & $\operatorname{IgG}$ Bo $1 / 400$ \\
\hline 18 & 4 a $10 \mathrm{~m}$ & $\mathrm{~F}$ & Capital & Quadril D & 1 mês & Contato & IgG Ba 1/3200 \\
\hline 19 & 2 a $6 \mathrm{~m}$ & $\mathrm{~F}$ & Capital & Quadril D de repetição $(2 x)$ & 15 dias & Contato & $\operatorname{IgM~Bo1/100~}$ \\
\hline 20 & $1 \mathrm{a} 11 \mathrm{~m}$ & M & Capital & Quadril D & 5 dias & Contato & $\operatorname{IgG}$ Ba $1 / 800$ \\
\hline
\end{tabular}

ELISA = Enzyme-linked immunosorbent assay; $\mathrm{a}=$ anos; $\mathrm{m}=$ meses; $\mathrm{F}=$ sexo feminino; $\mathrm{M}=$ sexo masculino; $\mathrm{D}=$ direito; $\mathrm{E}=$ esquerdo; Ig $\mathrm{M}=$ imunoglobulina $\mathrm{M}$; IgG = imunoglobulina G.

TABELA 3

Pacientes com oligoartrite aguda e sorologia positiva para

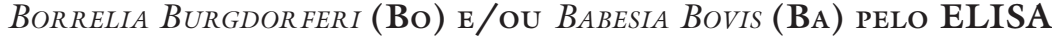

\begin{tabular}{|c|c|c|c|c|c|c|c|}
\hline $\mathrm{N}^{\circ}$ & Idade & Sexo & Procedência & Articulação acometida & Duração da doença & Picada ou contato & Sorologia (ELISA) \\
\hline 21 & $14 \mathrm{a}$ & $\mathrm{F}$ & Capital & Joelhos & 1 mês & Contato & $\operatorname{IgM}$ Bo1/100 \\
\hline 22 & $10 \mathrm{a}$ & M & Capital & Joelhos & 2 dias & Contato & IgG Ba1/25600 \\
\hline 23 & 4 a $10 \mathrm{~m}$ & M & Capital & Punhos & 7 dias & Contato & $\begin{array}{l}\text { IgG Bo } 1 / 400 \\
\operatorname{IgG} \text { Вa } 1 / 800\end{array}$ \\
\hline 24 & 2 a 6 m & $\mathrm{F}$ & Capital & Quadris & 15 dias & Contato & $\operatorname{IgM}$ Bo 1/100 \\
\hline 25 & 6 a $2 \mathrm{~m}$ & M & Interior & Joelhos & 6 meses antes & Contato & $\operatorname{IgG}$ Bo $1 / 800$ \\
\hline 26 & $7 \mathrm{a}$ & $\mathrm{F}$ & Interior & Joelhos & 3 meses antes & Picada há 6 meses & $\operatorname{IgG~Bo1/400~}$ \\
\hline 27 & 8 a $5 \mathrm{~m}$ & M & Interior & Joelhos & 1 mês & Contato & IgG Bo $1 / 400$ \\
\hline
\end{tabular}

ELISA = Enzyme-linked immunosorbent assay; $\mathrm{a}=$ anos; $\mathrm{m}=$ meses; $\mathrm{M}=$ sexo masculino; $\mathrm{F}=$ sexo feminino; $\mathrm{Ig} \mathrm{M}=$ imunoglobulina $\mathrm{M} ; \mathrm{IgG}=$ imunoglobulina $\mathrm{G}$.

\section{Tabela 4}

Pacientes COM Poliartrite aguda e sorologia positiva para Borrelia Burgdorferi (Bo) E/OU BABEsia BoVis (BA) PELO ELISA

\begin{tabular}{|c|c|c|c|c|c|c|c|}
\hline $\mathbf{N}^{\circ}$ & Idade & Sexo & Procedência & Articulações acometidas & Duração da doença & Picada ou contato & Sorologia (ELISA) \\
\hline 28 & 9 a $6 \mathrm{~m}$ & $\mathrm{~F}$ & Capital & Joelhos, tornozelos, punhos & 7 dias & Picada há 1 mês & $\begin{array}{l}\text { IgM Bo } 1 / 100 \\
\text { IgG Ba } 1 / 800\end{array}$ \\
\hline 29 & 9 a $9 \mathrm{~m}$ & $\mathrm{~F}$ & Capital & Joelhos, tornozelos, quadril direito & 2 dias & Contato & $\operatorname{Ig} M$ Bo $1 / 100$ \\
\hline
\end{tabular}

ELISA = Enzyme-linked immunosorbent assay; $\mathrm{a}=$ anos; $\mathrm{m}=$ meses; $\mathrm{M}=$ sexo masculino; $\mathrm{F}=$ sexo feminino; IgM = imunoglobulina $\mathrm{M} ; \mathrm{IgG}=\mathrm{imunoglobulina} \mathrm{G}$. 
TABela 5

Pacientes com artrite Crônica E SOROlogia positiva Para Borrelia BurgDorfERI (Bo) E/OU BABESIA BoVIS (BA) PELO ELISA

\begin{tabular}{|c|c|c|c|c|c|c|c|}
\hline $\mathrm{N}^{\circ}$ & Idade & Sexo & Procedência & Articulações acometidas & Duração da doença & Picada ou contato & Sorologia (ELISA) \\
\hline 30 & 5 a $4 \mathrm{~m}$ & $\mathrm{~F}$ & Capital & Monoartrite tornozelo D & 5 meses & Contato & $\begin{array}{l}\text { IgM Bo1/100 } \\
\text { IgG Ba } 1 / 800\end{array}$ \\
\hline 31 & 8 a $8 \mathrm{~m}$ & $\mathrm{~F}$ & Capital & Monoartrite tornozelo D & 7 meses & Picada há 9 meses & $\operatorname{Ig} M$ Bo1/100 \\
\hline 32 & 10 a $9 \mathrm{~m}$ & M & Capital & Oligoartrite (4), joelhos, tornozelos & 6 meses & Contato & IgG Ba 1/800 \\
\hline 33 & $5 \mathrm{a}$ & M & Capital & Monoartrite, joelho $\mathrm{E}$ & 1 ano & Contato & $\operatorname{IgG}$ Bo $1 / 400$ \\
\hline 34 & 4 a $7 \mathrm{~m}$ & $\mathrm{~F}$ & Interior & Monoartrite joelho D & 40 dias & Contato & $\operatorname{IgG}$ Ba $1 / 800$ \\
\hline 35 & $16 \mathrm{a}$ & M & Interior & Oligoartrite (4), joelhos e tornozelos & 2 a 7 meses & Contato & $\begin{array}{l}\operatorname{IgG} \text { Bo } 1 / 400 \\
\operatorname{IgG~Ba~} 1 / 1600\end{array}$ \\
\hline 36 & $5 \mathrm{a}$ & $\mathrm{F}$ & Interior & Poliartrite (8) mãos, punhos, joelhos e tornozelos & 45 dias & Contato & $\begin{array}{l}\text { IgG Bo } 1 / 400 \\
\operatorname{IgG~Ba~} 1 / 3200\end{array}$ \\
\hline
\end{tabular}

ELISA = Enzyme-linked immunosorbent assay; $a=$ anos; $m=$ meses; $M$ = sexo masculino; $F$ = sexo feminino; IgM = imunoglobulina $M$; IgG = imunoglobulina $\mathrm{G}$.

TABela 6

Pacientes com acometimento do Sistema nervoso Central e SOROlogia Positiva para BorReLia BURGDORFERI (Bo) E/OU BABESIA BOVIS (BA) PELO ELISA

\begin{tabular}{|c|c|c|c|c|c|c|c|}
\hline $\mathrm{N}^{\circ}$ & Idade & Sexo & Procedência & Tipo de acometimento & Duração da doença & Picada ou contato & Sorologia (ELISA) \\
\hline 37 & 5 a $9 \mathrm{~m}$ & M & Interior & Meningite linfocitária & 7 dias & Picada 1 mês & IgM Bo1/100 \\
\hline 38 & $11 \mathrm{a}$ & $\mathrm{F}$ & Interior & Paralisia facial & 14 dias & Contato & $\begin{array}{l}\text { IgM Bo } 1 / 100 \\
\text { IgG Ba } 1 / 3200\end{array}$ \\
\hline 39 & 10 a $7 \mathrm{~m}$ & M & Capital & Paralisia facial & 12 dias & Picada há 2 meses & IgG Ba 1/3200 \\
\hline 40 & 3 a $4 \mathrm{~m}$ & $\mathrm{~F}$ & Capital & Paralisia facial & 7 dias & Contato & IgG Bo $1 / 400$ \\
\hline
\end{tabular}

ELISA = Enzyme-linked immunosorbent assay; $a$ = anos; $m$ = meses; $M=$ sexo masculino; $F$ = sexo feminino; Ig M = imunoglobulina $M$; IgG = imunoglobulina $\mathrm{G}$.

Os pacientes com sintomatologia e sorologia positivas para $B$. burgdoferi foram tratados conforme o padronizado. Os pacientes com sorologia positiva, mas assintomáticos na época do acompanhamento não foram tratados. Durante esse seguimento, cinco pacientes com sorologia positiva apresentaram reagudização da artrite, sendo então introduzido a antibioticoterapia por 14 a 21 dias com remissão dos quadros. Os pacientes com outros acometimentos não apresentaram reagudização nem progressão da doença. Nenhum paciente evoluiu com acometimento de mais de um sistema. Os pacientes com sorologia positiva para Babesia bovis não foram tratados até o momento.

\section{DISCUSSÃO}

Revisando-se a literatura, a faixa etária pediátrica é freqüentemente afetada pelas diferentes manifestações da $\mathrm{DL}^{(2,6,38-41)}$. Neste estudo, a faixa etária escolar foi a mais acometida e não houve predomínio do sexo masculino, como ocorreu em alguns estudos ${ }^{(38-41)}$. A rotina diária das crianças, com atividades de lazer ao ar livre, pode torná-las mais suscetíveis às picadas de carrapato, que, geralmente, são contaminadas no próprio ambiente domiciliar, pois a distribuição dos carrapatos na natureza é bastante ampla e variada ${ }^{(42)}$. Esses podem estar presentes nos gramados de praças e residências, infectando conseqüentemente os animais domésticos de estimação, que são competentes reservatórios de Borrelia sp. ${ }^{(39)}$.

Em vários estudos epidemiológicos realizados tanto em adultos quanto em crianças, menos da metade dos pacientes recordavam a picada do carrapato antes do início dos sintomas, provavelmente pelo pequeno tamanho das ninfas, cujo potencial de infectividade para o homem é maior do que dos carrapatos adultos ${ }^{(20,42,43)}$. Neste estudo, somente $20 \%$ afirmaram que haviam sido picados por carrapatos.

Em estudos anteriores à lesão patognomônica cutânea, o EM esteve presente em $50 \%$ a $70 \%$ dos pacientes com DL, sendo a manifestação mais freqüente em crianças $^{(44)}$. 
No estudo presente, apenas um paciente apresentou esta lesão. Apresentaram lesão cutânea crônica apenas dois pacientes, caracterizadas como lesões em placa do tipo morféia e esclerodermia localizada linearmente em membro inferior direito. Lesões semelhantes à esclerodermia na DL têm sido descritas principalmente na Europa, com isolamento do agente etiológico (B. afzelii) ${ }^{(45)}$. No Brasil, em 1998, Costa et al. registraram a ocorrência de lesões esclerodérmica - like em adultos em Mato Grosso do Sul. Foi sugerido ainda neste estudo a existência de uma borreliose semelhante à européia no Estado ${ }^{(14)}$. Existem ainda relatos recentes na literatura de associação da Borrelia burgdorferi com a esclerodermia linear em golpe de sabre e com hemiatrofia facial progressiva ou síndrome de Parry-Romberg ${ }^{(25,46,47)}$.

A artrite de Lyme descrita na literatura geralmente é de evolução aguda e oligoarticular ${ }^{24,38,48)}$. Neste estudo, todos os pacientes com artrite aguda apresentaram remissão do quadro apenas com antiinflamatórios não-hormonais em l a 3 semanas, pois a sorologia foi realizada meses após a coleta. Em dois pacientes com recidiva da artrite, a antibioticoterapia com amoxicilina por 14 a 21 dias, na dose de $50 \mathrm{mg} / \mathrm{kg} /$ dia em três doses diárias, foi realizada.

Há relatos de recorrência da artrite e evolução para artrite crônica em 10\% dos pacientes, semelhantemente à artrite reumatóide juvenil (ARJ), sendo difícil o diagnóstico diferencial ${ }^{(49,50)}$. No presente estudo, cinco pacientes com artrite crônica apresentaram anticorpos contra Borrelia burgdorfer. Estes pacientes estavam sendo tratados como portadores de ARJ. Apresentaram IgM positivo (1/100) para B. burgdorferi dois pacientes e mantinham monoartrite em tornozelo mesmo após dois meses de tratamento com antiinflamatório não-hormonal. Com o resultado da sorologia, receberam amoxicilina por 21 dias, com remissão da artrite. Nos outros três pacientes, não foi introduzida a antibioticoterapia, pois já estavam em remissão por mais de seis meses no momento em que foi realizada a técnica sorológica.

$\mathrm{Na}$ Europa, a paralisia facial é a neuropatia periférica mais comum na DL, ocorrendo em 3\% das crianças com a doença e regredindo em duas a oito semanas, mesmo sem tratamento ${ }^{(2,51,52)}$. Neste estudo, a paralisia facial ocorreu em seis pacientes e a sorologia para B. burgdorferi foi positiva em dois. Um paciente com paralisia facial havia sido picado por carrapato dois meses antes e apresentou títulos altos de anticorpos da classe IgG para Babesia bovis (1:3200). Não existem relatos até o momento da babesiose humana cursando com paralisia facial. A positividade do anticorpo pode significar reação cruzada ou infecção prévia pela Babesia, que pode ser explicada pela presença apenas de IgG.

$\mathrm{Na}$ literatura, a alteração cardíaca mais freqüentemente relatada é o bloqueio cardíaco ${ }^{(53)}$. Neste estudo, uma paciente apresentou pericardite aguda sem etiologia definida, resolvida com antibioticoterapia por 14 dias (ceftriaxona) e a sorologia foi positiva para B. bovis (IgG 1:800). Por não existirem dados sobre a babesiose na infância com comprometimento cardíaco, não é possível afirmar que a pericardite tenha sido causada pela infecção por Babesia. É mais provável que a positividade signifique exposição prévia com infecção assintomática.

O ELISA contra B. burgdorferi mostrou positividade em $29 \%$ dos pacientes, sendo $17 \%$ para IgM e $12 \%$ para IgG. Estudos anteriores mostraram resultados com porcentagem maior que a encontrada neste estudo. Em um dos primeiros estudos realizados na faixa etária pediátrica, Williams et al. ${ }^{(41)}$ encontraram $73 \%$ de positividade para $B$. burgdorferi em 90 crianças com idade média de 9 anos que apresentaram EM associado às manifestações articulares ou do SNC em uma região endêmica de Nova York.

Gerber et al. ${ }^{(44)}$ relataram $37 \%$ de positividade de anticorpos contra B. burgdorferi em crianças com critérios clínicos e epidemiológicos de DL em Connecticut, em 1996. Os resultados encontrados no Brasil por Gauditano et al..$^{(54)}$ mostraram soropositividade pelo ELISA em pacientes com SLS de $38,89 \%$ para IgG e $36,11 \%$ para IgM.

A análise dos resultados sorológicos deve ser criteriosa e sempre correlacionada com a história clínica e epidemiológica dos pacientes. Os títulos de IgG elevados são mais característicos da fase tardia da doença. Sendo assim, a presença de IgG em pacientes com algumas semanas da doença sugere exposição prévia da mesma forma que sintomas crônicos não podem ser atribuídos à DL se somente a $\operatorname{IgM}$ estiver presente ${ }^{(19)}$. Os anticorpos da classe $\operatorname{IgM}$ tornam-se positivos após três a quatro semanas do estágio primário com pico em seis a oito semanas e regressão em quatro a seis meses. Já os níveis de $\operatorname{IgG}$ se elevam em seis a oito semanas após o início da infecção, atingem o pico em quatro a seis meses, e podem declinar após o tratamento, mas, geralmente, permanecem detectáveis por muitos anos, mesmo em pacientes assintomáticos ${ }^{(52)}$.

Os resultados encontrados no grupo-controle deste estudo ( $8 \%$ de positividade tanto para anticorpos da classe IgG quanto para $\operatorname{IgM}$ ) diferiram em porcentagem em relação a alguns relatos da literatura. Um estudo realizado em 1993 na Alemanha, em que amostras de 574 crianças saudáveis foram coletadas pelo período de dois anos, mostrou que a 
taxa de soroprevalência encontrada de anticorpo IgG foi de $2,6 \%$ e de $\operatorname{IgM} 0,7 \%^{(2)}$. No Brasil, Gauditano et al..$^{(54)}$ compararam pacientes com SLS com um grupo-controle constituído de 80 amostras de soros de doadores de sangue normais e encontraram positividade para IgG em 1,25\% e para IgM em 2,5\%. Essa diferença nos resultados do presente estudo pode ter ocorrido em virtude de a região do estudo ser propícia à disseminação dos vetores da SLS, e estes pacientes do grupo-controle, embora não preenchessem os critérios clínicos e epidemiológicos, poderiam ter tido exposição prévia com infecção assintomática.

A positividade da sorologia para B. bovis nos soros de pacientes com SLS para o anticorpo IgG (24\%) mostrouse aumentada quando comparada com o grupo-controle (3\%). Os resultados encontrados estão próximos aos descritos na literatura. No Brasil, Yoshinari et al. ${ }^{(34)}$ realizaram o teste ELISA para babesiose em 59 pacientes com SLS, e foram encontrados $16,9 \%$ de positividade de anticorpos IgG e $15,25 \%$ de IgM contra B. bovis. Ou seja, $25,42 \%$ dos pacientes com SLS apresentaram anticorpos para os antígenos da babesiose. Nesse mesmo estudo, o teste foi realizado também em um grupo de 49 indivíduos normais, a fim de se conhecer a freqüência da soropositividade para babesiose na população normal, e foi encontrada $8,2 \%$ de positividade para anticorpos IgG para Babesia bovise 2,04\% para $\operatorname{IgM}$, aproximando-se dos resultados encontrados no presente estudo para IgG. A positividade dos anticorpos contra Babesia bovis pode ser por causa da memória imunológica dos indivíduos testados, pois demonstrou-se que os anticorpos anti-babesia podem se manter detectáveis pelo período de um a dois anos após a infecção primária, mesmo assintomática ${ }^{(21)}$. Nenhum paciente deste estudo apresentou $\operatorname{IgM}$ positivo contra B. bovis.

Ainda em relação ao grupo-controle, em um outro estudo realizado em Cuba, foram detectados anticorpos contra Babesia bovis pelo ELISA em 3,9\% dos doadores de sangue ${ }^{(55)}$.

Em relação aos resultados positivos obtidos neste trabalho, devemos considerar que em publicações de autores brasileiros ${ }^{(8,10,13-15,18)}$, ficou demonstrado que tendo a B. burgdorferi como substrato, o teste ELISA mostrou maior sensibilidade diagnóstica que o método de WB. Esta observação levou o Centro de Referência para a DL no Brasil da FMUSP, a considerar o teste de ELISA como exame de triagem para aqueles pacientes que tenham epidemiologia e clínica positivas. Porquanto, os casos positivos ao ELISA devem ser submetidos ao exame de WB para confirmação.
Neste trabalho, o objetivo foi realizar a triagem laboratorial inicial nos soros das crianças que apresentassem critérios clínicos e epidemiógicos, preconizados pelo Centro de Referência para a DL, no Brasil, da FMUSP.

Por outro lado, Costa et al.(14,15) demonstraram que os pacientes que tiveram reatividade contra B. burgdorferi pelo método ELISA foram positivos no $\mathrm{WB}$ e as bandas detectadas não apresentavam os pesos moleculares das proteínas descritas e preconizadas para confirmação diagnóstica pelo Centro de Controle de Doenças (CDC, EUA $)^{(8,9,13)}$.

Ainda assim, considera-se imprescindível a realização do WB com achado de, no mínimo, duas bandas de IgM ou quatro de $\mathrm{IgG}$, isoladamente, ou de uma banda de IgM e duas de IgG, concomitantemente, para confirmação diagnóstica ${ }^{(8,9)}$.

Apesar de espiroquetídeos terem sido observados no Brasil, em amostras de soro e cultura de sangue de pacientes com quadro clínico compatível com a SLS, não se conseguiu ainda o isolamento e a caracterização do agente etiológico. Além disso, as tentativas de amplificação do DNA do gênero Borrelia sp., por meio da técnica de PCR a partir do soro, líquores e de meios de culturas mostraram-se infrutíferas até este momento ${ }^{(13,16,18)}$.

Esses fatos, aliados à difícil resposta terapêutica que os pacientes com sorologia e clínica compatíveis com SLS têm apresentado nos estudos nacionais, sugerem que o(s) agente(s) etiológico(s) desta síndrome devem ser de genoespécie diferente daquelas observadas nos Estados Unidos, Europa e Ásia.

Concluindo, foi encontrada uma freqüência superior de anticorpos contra Borrelia e Babesia nos pacientes em relação aos controles. Embora pequena, essa diferença foi estatisticamente significante. Esse achado não atesta que o quadro clínico dos pacientes seja causado por espécies de Borrelia ou Babesia, mas levantam a possibilidade de participação de algum agente infeccioso que possa estar relacionado a esses microrganismos. É importante frisar também que os controles foram todos provenientes de área urbana, enquanto parte dos pacientes com sorologia positiva foram provenientes de zona rural, e conseqüentemente podem ter sido repetidamente expostos ao contato com estes agentes infecciosos.

Portanto, os soros que tiveram resultados positivos pelo ELISA, neste trabalho, deverão ser submetidos à confirmação pelo WB, e os resultados correlacionados com a clínica e à epidemiologia de cada paciente. 


\section{AGRADECIMENTOS}

Agradecemos aos médicos que encaminharam pacientes para a pesquisa e à médica veterinária Dra. Maria Aparecida C. Cunha, aos bioquímicos Dr. César A. Arão e Dra. Iza Keiko Hirai Akamine e à bióloga Márcia Cristina Correa Chagas pelo inestimável auxílio na realização dos ensaios imunoenzimáticos.

\section{REFERÊNCIAS}

1. Nadelman RB, Wormser GP: Lyme borreliosis. Lancet 352: 557-65, 1998.

2. Christen HJ, Hanefeld F, Eiffert H, et al.: Epidemiology and clinical manifestations of Lyme borreliosis in childhood: a prospective multicentre study with special regard to neuroborreliosis. Acta Paediatr Suppl 386: 1-76, 1993.

3. Ornstein K, Berglund J, Bergström S, Norrby R, Barbour AG: Three major Lyme Borrelia genospecies (Borrelia burgdorferi sensu stricto, B. afzelii and B. garinii) identified by PCR in cerebrospinal fluid from patients with neuroborreliosis in Sweden. Scand J Infect Dis 34: 341-6, 2002.

4. Masuzawa T: Terrestrial distribution of the Lyme borreliosis agent Borrelia burgdorferi sensu lato in east Asia. Jpn J Infect Dis 57: 229-35, 2004.

5. Fonseca AH, Salles RS, Salles SAN, Madureira RC, Yoshinari NH: Borreliose de Lyme símile: uma doença emergente e relevante para a dermatologia no Brasil. An Bras Dermatol 80(2): 171-8, 2005.

6. Hengge UR, Tannapfel A, Tyring SK, Erbel R, Arendt G, Ruzicka T: Lyme borreliosis. Lancet Infect Dis 3 (8): 489-500, 2003.

7. Steere AC, Malawista SE, Snydman DR, et al.: Lyme arthritis: an epidemic of oligoarticular arthritis in children and adults in three Connecticut communities. Arthritis Rheum 20: 7-17, 1977.

8. Yoshinari NH, Steere AC, Cossermelli W: Revisão da Borreliose de Lyme. Rev Ass Med Bras 35: 34-7, 1989.

9. Yoshinari NH, Barros PJL, Yassuda P, Baggio D, Steere AC, Cossermelle W: Estudo epidemiológico da doença de Lyme no Brasil. Rev Hosp Clin Fac Med São Paulo 47: 71-5, 1992.

10. Yoshinari NH, Oyafuso LK, Monteiro FGV, et al.: Doença de Lyme: relato de um caso observado no Brasil. Rev Hosp Clin Fac Med São Paulo 48: 170-4, 1993.

11. Barros PJL, Levy LH, Monteiro FGV, Yoshinari NH. Doença de Lyme. Acometimento cutâneo e tratamento das fases iniciais. Rev Assoc Med Bras 39: 170-2, 1993.

12. Barros PJL, Bonoldi V, Yoshinari NH: Características clínicas da doença de Lyme no Brasil. Rev Bras Reumatol 36(2): 67-74, 1996.

13. Yoshinari NH, Barros PJL, Bonoldi VLN, et al.: Perfil da borreliose de Lyme no Brasil. Rev Hosp Clin Fac Med São Paulo 52: 111-7, 1997.

14. Costa IP, Bonoldi VLN, Yoshinari NH: Perfil clínico e laboratorial da doença de Lyme-Símile no estado de Mato Grosso do Sul: análise de 16 pacientes. Rev Bras Reumatol 41 (3): 142-150, 2001.

15. Costa IP, Yoshinari NH, Barros PJL, et al.: Doença de Lyme em Mato Grosso do Sul: relato de três casos clínicos, incluindo o primeiro relato de meningite de Lyme no Brasil. Rev Hosp Clin Fac Med São Paulo 51: 253-7, 1996.

16. Costa IP, Bonoldi VLN, Yoshinari NH: Search for Borrelia sp. in ticks collected from potential reservoirs in an urban forest reserve in the state of Mato Grosso do Sul, Brazil: a short report. Mem Inst Oswaldo Cruz 97(5): 631-5, 2002.

17. Eskow E, Adelson ME, Raja-Venkitesh S, Mordechai E: Evidence for disseminated Mycoplasma fermentans in New Jersey residents with antecedent tick attachment and subsequent musculoskeletal symptoms. J Clin Rheumatol 9(2): 77-87, 2003.

18. Gauditano G, Bonoldi VLN, Costa IP, et al.: Síndrome de LymeSímile ou complexo infecto-reacional do carrapato - síndrome de Baggio-Yoshinari. Rev Paulista Reumatol 4 (3): 17, 2005.

19. Soares CO, Costa IP, Naka EN, et al.: Caracterização clínica, epidemiológica e laboratorial da Borreliose de Lyme e a coexistência com a Babesiose em humanos e bovinos no Estado de Mato Grosso do Sul. In press. 2006.

20. Lo Re III V, Occi JL, Macgregor RR: Identifying the vector of Lyme disease. Am Fam Physician 69: 1935-7, 2004.

21. Loa CC, Adelson ME, Mordechai E, Raphaelli I, Tilton RC: Serological diagnosis of human babesiosis by IgG Enzyme-linked immnusorbent assay. Curr Microbiol 49: 385-9, 2004.

22. Lipsker D, Antoni-Bach N, Hansmann Y, Jaulhac B: Long-term prognosis of patients treated for erythema migrans in France. $\mathrm{Br}$ J Dermatol 146: 872-6, 2002.

23. Melo IS, Gadelha AR, Ferreira LCL: Estudo histopatológico de casos de eritema crônico migratório diagnosticados em Manaus. An Bras Dermatol 78:169-77, 2003.

24. Huppertz HI, Bentas W, Haubitz I, et al.: Diagnosis of paediatric Lyme arthritis using a clinical score. Eur J Pediatr 157: 304-8, 1998.

25. Wackernagel A, Bergmann AR, Aberer E: Acute exacerbation of systemic scleroderma in Borrelia burgdorferi infection. J Eur Acad Dermatol Venereol 19(1): 93-6, 2005.

26. Brzonova I, Wollenberg A, Prinz JC: Acrodermatitis chronica atrophicans affecting all four limbs in an 11 -year-old-girl. Br J Dermatol 147: 375-8, 2002.

27. Christen HJ: Lyme neuroborreliosis in children. Ann Med 28: 235-40, 1996.

28. Escudero-Nieto R, Guerrero-Espejo A: Enfermedades producidas por Borrelia. Enferm Infect Microbiol Clin 23(4): 232-40, 2005.

29. Soares CO: Princípios, padronização e validação das provas sorológicas - técnicas imunoenzimáticas. In: Madruga CR, Araújo FR, Soares CO, editors. Imunodiagnóstico em medicina veterinária. Campo Grande: Embrapa Gado de Corte; 2001. p.145-75.

30. Cermakova Z, Ryskova O, Honegr K, Cermakova E, Hanovcova I: Diagnosis of Lyme borreliosis using enzyme immunoanalysis. Med Sci Monit 11 (4): 121-5, 2005.

31. Stone EG, Lavombe EH, Rand PW: Antibody testing and Lyme disease risk. Emerg Infect Dis 11 (5): 722-4, 2005.

32. Blaauw AAM, Van Loon AM, Schellekens JFP, Bijlsma JWJ: Clinical evaluation of guidelines and two-test approach for Lyme disease. Rheumatology 38: 1121-6, 1999. 
33. Craven RB, Quan TJ, Bailey RE, et al.: Improved serodiagnostic testing for Lyme disease: results of a multi center serologic evaluation. Emerg Infect Dis 2: 136-40, 1996.

34. Yoshinari NH, Abrão MG, Bonoldi VLN, et al.: Coexistence of antibodies to tick-borne agents of Babesiosis and Lyme borreliosis in patients from Cotia County, state of São Paulo, Brazil. Mem Inst Oswaldo Cruz 98 (3): 311-8, 2003.

35. White DJ, Talarico J, Chang HG, Birkhead GS, Heimberger T, Morse DL: Human babesiosis in New York State: review of 139 hospitalized cases and analysis of prognostic factors. Arch Intern Med 158: 2149-54, 1998.

36. Krause PJ, Telford SR, Pollack RJ, et al.: Babesiosis: an underdiagnosed disease of children. Pediatrics 89: 1045-8, 1992.

37. Stanczak J, Gabre RM, Kruminis-Lozowska W, Racewicz M, Kubica-Biernat B: Ixodes ricinus as a vector of Borrelia burgdorferi sensu lato, Anaplasma phagocytophilum and Babesia microti in urban and suburban forests. Ann Agric Environ Med 11: 109-14, 2004.

38. Saulsbury, Frank T: Lyme Arthritis in 20 children residing in a non-endemic area. Clin Pediatr 44 (5): 419-21, 2005.

39. Eichenfield AH, Goldsmith DP, Benach JL, et al.: Childhood Lyme arthritis: experience in an endemic area. J Pediatr 109 (5): 753-8, 1986.

40. Huppertz HI: Lyme disease in children. Curr Opin Rheumatol $13: 434-9,2001$

41. Williams CL, Strobino B, Lee A, et al.: Lyme disease in childhood: clinical and epidemiologic features if ninety cases. Pediatr Infect Dis J 9: 10-4, 1990.

42. Klein JD, Eppes SC, Hunt P: Envirommnetal and life-style risk factors for Lyme disease in children. Clin Pediatr (Phila) 35(7): 359-63, 1996.

43. Goossens HAT, Bogaard AE, Nohlmans MKE: Dogs as sentinels for human Lyme borreliosis in the Netherlands. J Clin Microbiol 39(3): 844-8, 2001.

44. Gerber MA, Shapiro ED, Burke GS, Parcells VJ, Bell GL: Lyme disease in children in southeastern Connecticut. N Engl J Med 335: 1270-4, 1996
45. Goodlad JR, Davidson MM, Gordon P, Billington R, Ho-Yen DO: Morphoea and Borrelia burgdorferi: results from the Scottish Highlands in the context of the world literature. J Clin Pathol 55: 374-8, 2002.

46. Salpietro DC, Merlino MV, Bruglia S, Guarneri F, Vaccaro M: Linear scleroderma 'en coup de sabre' associated with facial atrophy in a patient seropositive for Borrelia burgdorferi: a true case of molecular mimicry? Pediatr Allergy Immunol 15: 570-2, 2004

47. Sahin MT, Baris S, Karaman A: Parry-Romberg syndrome: a possible association with borreliosis. J Eur Acad Dermatol Venereol 18: 204-7, 2004

48. Renaud I, Cachin C, Gerster JC: Good outcomes of Lyme arthritis in 24 patients in an endemic area for Switzerland. Joint Bone Spine 71: 39-43, 2004.

49. Ecklund K, Vargas S, Zurakowski D, Sundel RP: MRI features of Lyme arthritis in children. AJR Am J Roentgenol 184: 1904-9, 2005

50. Hendrickx G, De Boeck H, Gossens A, Demanet C, Vandenplas Y: Persistent synovitis in children with Lyme arthritis: two unusual cases. An immunogenetic approach. Eur J Pediatr 163: 646-50, 2004.

51. Niemann G, Köksal MA, Oberle A, Michaelis R: Facial palsy and Lyme borreliosis: long-term follow-up of children with antibiotically untreated "idiopathic" facial palsy. Klin Pädiatr 209: 95-9, 1997

52. Vázquez M, Sparrow SS, Shapiro ED: Long-term neuropsychologic and health outcomes of children with facial nerve palsy attributable to Lyme disease. Pediatrics 112 (2): 93-7, 2003.

53. Karadag B, Spieker LE, Schwitter J, et al.: Lyme carditis. Cardiology in Review 12: 185-7, 2004.

54. Gauditano G, Bonoldi VLN, Hiratsuka RC, Kiss MH, Yoshinari $\mathrm{NH}$ : Aspectos imunológicos comuns entre a doença de Lyme e a febre reumática. Rev Bras Reumatol 40 (1): 1-8, 2000.

55. Hernandez MS, Castellano MA, Martínez RP, Pérez BS, Gonzáles JRB, Sibello AS: Pesquisaje de Babesia em trabajadores agropecuários y donantes em la província de Ciego de Avila. Rev Cubana Med Trop 49(2): 130-5, 1997. 